\title{
Hybrid Nanocomposites Based on Epoxy/silsesquioxanes Matrices Reinforced with Multi-walled Carbon Nanotubes
}

\author{
Marcelo Alexandre De Farias ${ }^{a, b} *$, Luiz Antônio Ferreira Coelho ${ }^{a}$, Sérgio Henrique Pezzin ${ }^{a}$
}

\author{
${ }^{a}$ Center of Technological Sciences, Universidade do Estado de Santa Catarina - UDESC, \\ Rua Paulo Malschitzki, 200, Zona Industrial Norte, CEP 89219-710, Joinville, SC, Brazil \\ ${ }^{b}$ Brazilian Nanotechnology National Laboratory - LNNano/CNPEM, Rua Giuseppe Máximo Scolfaro, \\ 10.000, Polo II de Alta Tecnologia de Campinas, CEP 13083-970, Campinas, SP, Brazil
}

Received: August 13, 2015; Revised: August 13, 2015; Accepted: October 14, 2015

\begin{abstract}
The aim of this work was the synthesis of hybrid organic-inorganic epoxy-copolysilsesquioxane nanocomposites reinforced with multi-walled carbon nanotubes (MWCNT). Copolysilsesquioxanes oligomers from 3-aminopropyltriethoxysilane (APTES) and phenyltriethoxysilane (PTES) precursors have been synthesized by a sol-gel process and chemically incorporated to an epoxy resin based on diglycidyl ether of bisphenol A (DGEBA). MWCNT (0.25 wt $\%)$ was added to the hybrid matrixes with different degrees of condensation. Fourier transform infrared analysis showed that a high degree of cure was achieved, suggesting that the MWCNT did not affect the curing reaction of the hybrid matrixes. Hybrid nanocomposites obtained by sonication technique presented improvement on thermal stability, exhibiting onset degradation temperatures higher than $340{ }^{\circ} \mathrm{C}$ under $\mathrm{N}_{2}$. Tensile tests presented Young's modulus and maximum stress values up to $2.9 \mathrm{GPa}$ and $47 \mathrm{MPa}$, respectively, indicating that the new hybrid epoxy/MWCNT nanocomposites show a moderate enhancement of the mechanical properties in comparison with the neat epoxy resin.
\end{abstract}

Keywords: epoxy resin, silsesquioxanes, carbon nanotubes, hybrid nanocomposite

\section{Introduction}

Epoxy resins are one of the most important classes of thermosetting polymers being applied in advanced composites mainly due to its chemical resistance, high tensile and compressive strength, low shrinkage during cure process and satisfactory adhesion, as well as structural stability and ease of processing ${ }^{1-3}$.

An usual method to enhance epoxy properties is the chemical modification by inorganic structures. Silsesquioxanes are typical organic-inorganic materials and can be incorporated into almost any kind of thermoplastic or thermosetting polymer to improve their properties ${ }^{4}$. Epoxy/silsesquioxane hybrids present improvements in thermal stability ${ }^{5}$, dielectric properties $^{6}$, corrosion resistance ${ }^{7}$, and mechanical properties ${ }^{8}$, as well as reduced flammability ${ }^{9}$, in comparison with neat epoxy resin. In this context, increases in glass transition temperature $\left(T_{\mathrm{g}}\right)$ with chemical modifications of epoxy matrixes by random ${ }^{10}$ or organized ${ }^{11}$ structures with polysilsesquioxanes are scarcely reported. Ni \& Zheng ${ }^{10}$ studied the chemical modification of DGEBA epoxy resins by the addition of poly(phenylsilsesquioxane). The authors related an increase of $6{ }^{\circ} \mathrm{C}$ in the $T_{\mathrm{g}}$ value of the epoxy/silsesquioxane system with the incorporation of $5 \mathrm{wt} \%$ silsesquioxane, however, the addition of 15 and $20 \mathrm{wt} \%$ of silsesquioxane reduced the epoxy $T_{\mathrm{g}}$ values in 4 and $6{ }^{\circ} \mathrm{C}$, respectively. $\mathrm{Wu}$ and co-workers ${ }^{12}$ produced a functional polyhedral oligomeric silsesquioxane (POSS) with two epoxy groups, which was incorporated in an epoxy resin, resulting in a hybrid

*e-mail: marcelo.farias@lnnano.cnpem.br material with improved flame retardancy and thermal stability. Furthermore, the authors proposed the degradation mechanism of this hybrid material, suggesting that the POSS is responsible to retard the movement and scission of epoxy polymeric chains, forming a stable charred layer that prevents the underlying materials from further combustion. In our previous work $^{13}$, an epoxy/silsesquioxane containing amino and phenyl groups was successfully synthesized with a novel interpenetrating network approach. The co-condensation of the silsesquioxanes were obtained with different degrees of condensation showing the possibility to control the sol-gel process in order to produce liquid silsesquioxanes oligomers that can be used as reactive precursors for further chemical modifications, e.g. between amino groups and epoxy groups. This combination leads to an epoxy/silsesquioxane hybrid matrix with potential for coating and structural applications.

Nanocomposites between epoxy resins and carbon nanotubes (CNT) are well known $n^{1,14,15}$. The current interest on the use of nanometer reinforcement in polymeric matrixes is due to the ability of these fillers to provide potentially unique properties to the polymer material as a result of their nanometer dimension. A number of materials can be produced at nanometer size, but carbon nanotubes (CNT) have gained much attention due to its exceptional aspect ratio (over 1000), low density, high strength and rigidity $^{14,16}$. However, in general, an homogeneous dispersion of nanoparticles throughout the matrix is required in order to benefit from its excellent reinforcement characteristics. Sonication techniques and mechanical mixing with high 
speed shearing are the most effective way to improve the dispersion of CNT in a polymer matrix ${ }^{17,18}$.

In the present work the synthesis and characterization of novel nanocomposites based on hybrid epoxy/silsesquioxanes matrixes reinforced with multi-walled carbon nanotubes (MWCNT) was investigated. The nanocomposites were characterized by Fourier transform infrared spectroscopy (FTIR), scanning electron microscopy (SEM), dilatometry, thermogravimetry (TGA) and mechanical tensile tests.

\section{Experimental}

\subsection{Materials}

Araldite LY 1316 epoxy resin $\left(\right.$ epoxy value $\left.=6.5 \mathrm{eq} \mathrm{kg}^{-1}\right)$ based on bisphenol A diglycidyl ether (DGEBA) monomer and Aradur HY 1208 hardener (amine value $=950 \mathrm{mg} \mathrm{KOH} \mathrm{g}^{-1}$ ) were purchased from Huntsman. MWCNT Baytubes ${ }^{\circledR} \mathrm{C} 150$ HP (Lot-No: E0009AAD07; Drum-No: 034) were kindly supplied by BAYER Materials Science. APTES (99.9\%) and PTES (99.5\%) were purchased from Sigma-Aldrich (St. Louis, USA).

\subsection{Synthesis of copolysilsesquioxane APTES/ PTES and hybrid epoxy/silsesquioxanes preparation}

The syntheses of copolysilsesquioxane from equimolar mixture of APTES and PTES, as well as the DGEBA matrix chemical modification with APTES/PTES copolysilsesquioxanes, were conducted as reported in a previous work ${ }^{13}$. Briefly, the hydrolysis and condensation reactions of APTES and PTES were acid catalyzed $(\mathrm{HCl} 0.1 \mathrm{M})$ and interrupted after 18 or $24 \mathrm{~h}$, achieving condensation degrees of 76 and $81 \%$, respectively. The viscous product (APTES/PTES copolysilsesquioxane) reacted with DGEBA matrix producing hybrid organic-inorganic with $7.5 \mathrm{wt} \%$ copolysilsesquioxane mass fraction. Scheme 1 illustrates the copolysilsesquioxane oligomer chemically bonded to epoxy matrix.

\subsection{Nanocomposite processing}

Propanone (20 wt\%) and MWCNT (0.25 wt\%) percentages relative to the hybrid total mass - were sonicated at 165 W (Sonics Vibra Cell, VCX 750 W) during 20 minutes. The hybrid epoxy/silsesquioxane was then added to the propanone/MWCNT system which was sonicated for $30 \mathrm{~min}$ at $187.5 \mathrm{~W}^{[17]}$ with simultaneously magnetic stirring ${ }^{17,18}$. The solvent was removed under vacuum at $65^{\circ} \mathrm{C}$ until constant mass.

The nanocomposite curing process (using polyamine-based hardener) was performed by two methodologies: (a) curing immediately after chemical modification of the DGEBA resin with the copolysilsesquioxane, and (b) curing after 7 days of the chemical modification, in order to allow the formation of higher molecular weight hybrids ${ }^{13}$. In both methods 12 phr of hardener were added and the homogenization was conducted mechanically for 5 minutes at $250 \mathrm{rpm}$. Then, the hybrid nanocomposites were cured in specific templates

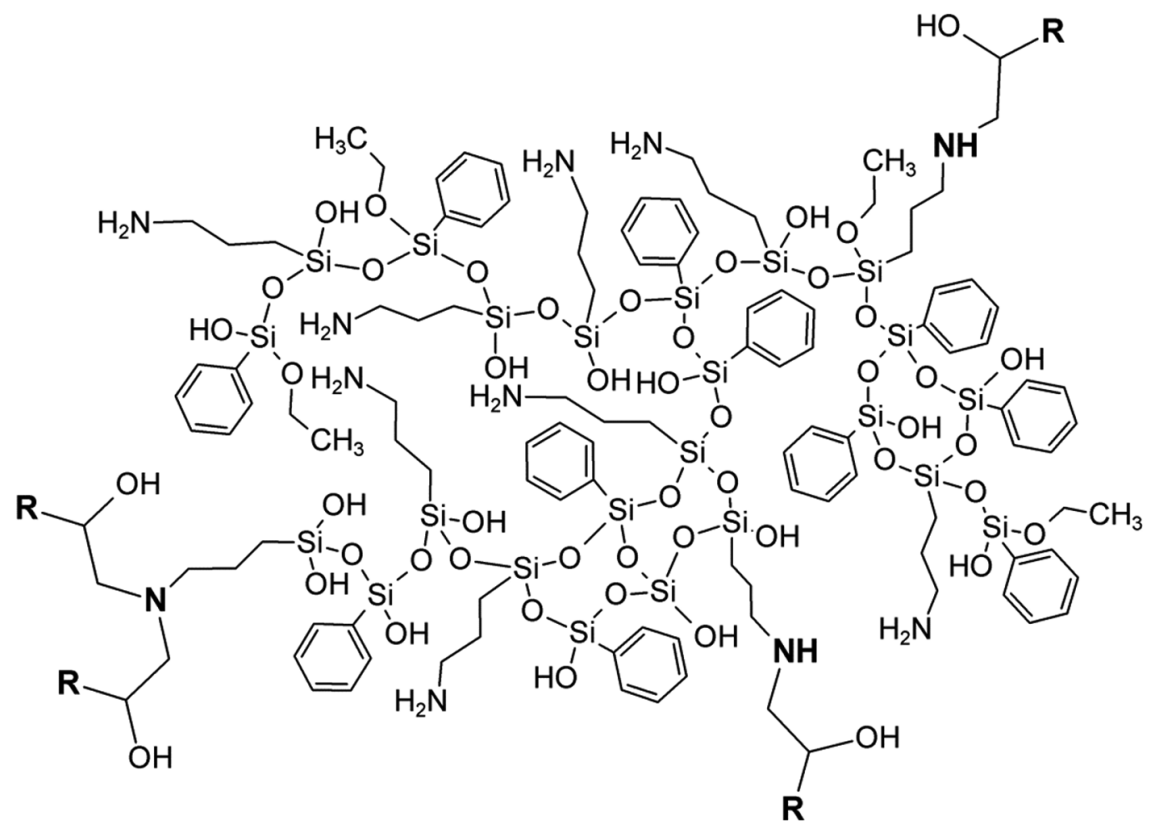<smiles>[R]=CCc1cccc(C(C)(C)c2cccc(OCC(O)COc3ccc(C(C)(C)c4ccc([O-])cc4)cc3)c2)c1</smiles>

Scheme 1. Chemical structure of epoxy-APTES/PTES silsesquioxane hybrid matrix. Numbers 1 and 2 shows the possible nitrogen bonds from the reaction between APTES amine groups with one or two DGEBA epoxy groups, respectively. 
(e.g. dilatometry and mechanical tests) for $2 \mathrm{~h}$ at $80^{\circ} \mathrm{C}$ and subsequently submitted at $160^{\circ} \mathrm{C}$ for another $2 \mathrm{~h}^{[10]}$.

The samples were named according to Table 1. Briefly, LY refers to DGEBA resin; 18 or 24 indicate the hydrolysis and condensation reaction times (in hours); 0 or 7 , is the cure gap after chemical modification (in days); CNT, indicated the MWCNT incorporation $(0.25 \mathrm{wt} \%)$. Thus, LY-18-7-CNT is the hybrid nanocomposite with APTES/PTES copolysilsesquioxane obtained by $18 \mathrm{~h}$ of sol-gel process, cured 7 days after chemical modification and containing $0.25 \mathrm{wt} \%$ MWCNT.

\subsection{Characterization}

FTIR analyses were performed on a Perkin-Elmer Spectrum One B in attenuated total reflectance (ATR) mode, with resolution of $4 \mathrm{~cm}^{-1}$ and range between $4000-650 \mathrm{~cm}^{-1}$.

Morphological characterization was conducted in a scanning electron microscope (SEM) Zeiss DSM 940A operating at an accelerating voltage of $20 \mathrm{kV}$. Tensile fracture surfaces of samples were coated with a thin gold layer on a Baltec SCD 050 sputter coater.

$T_{\mathrm{g}}$ values were obtained from dilatometry analyses performed on a Netzsch $402 \mathrm{C}$ Dilatometer. $T_{\mathrm{g}}$ is determined by dilatometry from the $\Delta \mathrm{L} / \mathrm{L}_{\mathrm{o}}$ curve as the point of intersection of the tangents below and above the slope change, according to ASTM E1545 ${ }^{[19]}$. Typically, the samples ca. $22 \times 5 \times 5 \mathrm{~mm}$ were heated from $30^{\circ} \mathrm{C}$ to $160^{\circ} \mathrm{C}$ at $10 \mathrm{~K} \mathrm{~min}^{-1}$ heating rate under nitrogen atmosphere. Then the samples were cooled and a second heating cycle was done under the same conditions as before, eliminating the samples' thermal history.

Thermogravimetric analyses (TGA) were conducted on a Netzsch STA 449C. The samples ca. $15 \mathrm{mg}$ were heated from $30{ }^{\circ} \mathrm{C}$ to $900{ }^{\circ} \mathrm{C}$ under a heating rate of $10 \mathrm{~K} \mathrm{~min}^{-1}$ under nitrogen atmosphere.

Mechanical tests were carried out in a universal mechanical testing machine (Emic DL 30000), according to ASTM D638 $8^{[20]}$.

\section{Results and Discussion}

\subsection{Epoxy/silsesquioxanes hybrid nanocomposites: spectroscopic analysis}

Although the cure process of epoxy resins starts with hardener addition, the APTES/PTES copolysilsesquioxane is also able to open the epoxy ring as well as the hardener. The primary amine group present in APTES reacts with epoxy ring turning into secondary amine. Furthermore, the secondary amine may react with another epoxy ring producing a tertiary amine (Scheme 1). This is an autocatalytic process once hydroxyls formed can also open epoxy rings ${ }^{4,21}$. However, the concentration of amine groups present in the copolysilsesquioxane is unable to promote the total cure process and, thus, the hybrids were further cured with a polyamine-based hardener.

The cure degrees of the epoxy matrix were verified by FTIR analysis as shown in Figure 1. The characteristic

Table 1. Schematic nomenclature of the samples.

\begin{tabular}{ccccc}
\hline Sample name & DGEBA resin & $\begin{array}{c}\text { Hydrolysis and condensation } \\
\text { reaction times (h) }\end{array}$ & Cure gap (day) & $\mathbf{0 . 2 5}$ wt\% MWCNT \\
\hline LY & LY & - & - & - \\
LY-CNT & LY & - & - & CNT \\
LY-18-0-CNT & LY & 18 & 0 & CNT \\
LY-18-7-CNT & LY & 18 & 7 & CNT \\
LY-24-0-CNT & LY & 24 & 0 & CNT \\
LY-24-7-CNT & LY & 24 & 7 & CNT \\
\hline
\end{tabular}

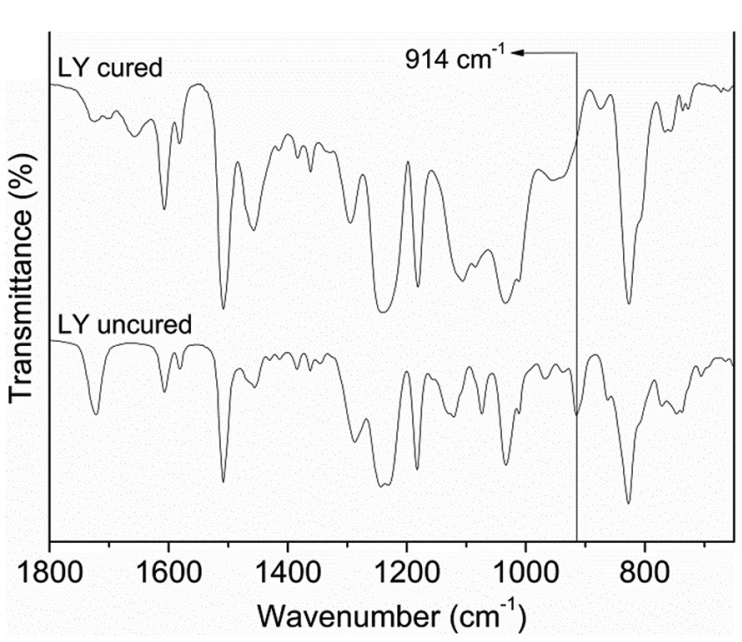

(a)

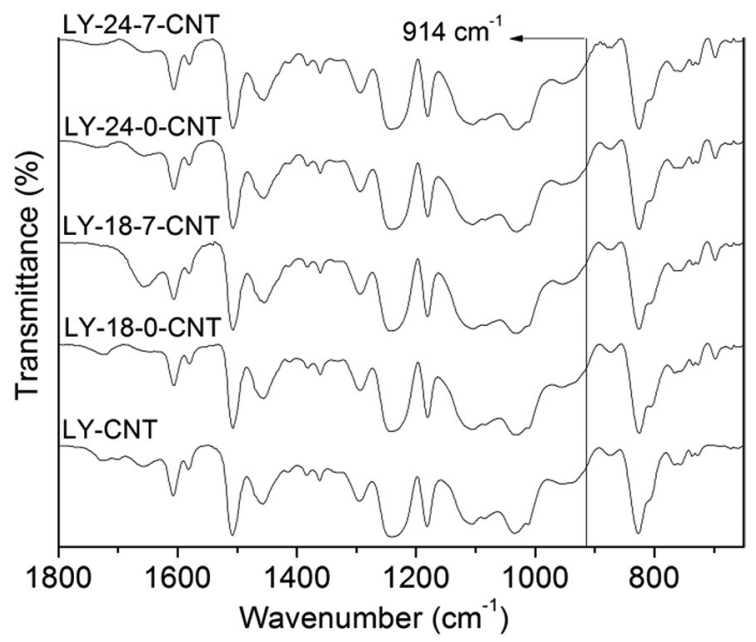

(b)

Figure 1. (a) FTIR spectra of uncured and cured LY matrix. (b) FTIR spectra of cured hybrid nanocomposites. 
absorption peak of epoxy ring appeared in $950-810 \mathrm{~cm}^{-1}$ range ${ }^{22}$. This region is attributed to the asymmetric axial stretching of the epoxy ring, where the $\mathrm{C}-\mathrm{C}$ bond is elongated during the contraction of the $\mathrm{C}-\mathrm{O}$ bond. The DGEBA epoxy resin showed the epoxy ring stretching band at $914 \mathrm{~cm}^{-1}$. Figure 1a also shows clearly the extinction of the characteristic epoxy ring absorption peak in the DGEBA epoxy resin cured ("LY cured") in relation to the uncured neat epoxy resin ("LY uncured"). This behavior was also observed in Figure 1b, indicating that a high degree of cure was achieved with the applied cure conditions. Although some reports have shown that CNT may change the cure reaction parameters of epoxy resins $^{23-25}$, the FTIR spectra also show that the incorporation of $0.25 \mathrm{wt} \%$ MWCNT did not affect the final cure process of the neat or hybrid epoxy matrix. No spectroscopic change was observed with the incorporation of the MWCNT due, probably, to the low concentration of MWCNT presented in the nanocomposite and also because no reaction between MWCNT and epoxy/silsesquioxanes was expected.

The spectra of samples presented in Figure 1 are very similar. The analysis of Si-C bending at approximately $700 \mathrm{~cm}^{-1}$ is necessary in order to differentiate these spectra. Figure 2 compares the characteristic absorption band relative to $\mathrm{Si}-\mathrm{C}$ bending presented in the hybrid matrixes. Since only hybrid matrixes have Si-C bonds (Scheme 1), the LY matrix did not present absorption band in the specific region of $715-670 \mathrm{~cm}^{-1}$. On the other hand, the APTES/PTES copolysilsesquioxane present $\mathrm{Si}-\mathrm{C}$ bonds in your structure. Furthermore, hydroxyls from silanol groups can also open epoxy rings during the cure reaction ${ }^{4,21}$, forming new Si-C bonds between the APTES/PTES copolysilsesquioxane and the LY matrix. For these reasons, the hybrid matrixes presented $\mathrm{Si}-\mathrm{C}$ absorption bands and the hybrid matrices cured after 7 days of chemical modification presented slightly higher intensity for the $\mathrm{Si}-\mathrm{C}$ bonds, comparing with the respective hybrid matrices cured immediately after chemical modification.

\subsection{Morphology characterization}

Figure 3 exhibits SEM images of epoxy and hybrid nanocomposites surfaces after tensile fractures. All samples showed typically brittle fracture morphologies, moreover, it was not possible to observe significant changes in the matrices' fracture mechanisms with the addition of $0.25 \mathrm{wt} \%$ MWCNT. In our previous work ${ }^{17}$, we observed a similar behavior when carboxylated single-walled carbon nanotubes (SWCNT) were incorporated to similar epoxy resin.

On the other hand, regions with high concentration of MWCNT were also observed in the fracture surfaces of nanocomposites. Figure 4 highlights these concentrated regions spread by the fracture surface (white dots) on the LY-18-0-CNT hybrid matrix. Although the MWCNT showed good interaction with epoxy/silsesquioxane hybrid matrix, such remaining agglomerations can contribute to a localized stress concentration and consequently reduce the composite's stiffness ${ }^{14,16,26}$.

\subsection{Thermal properties}

Dilatometric analyses were used to evaluate the $T_{\mathrm{g}}$ of the nanocomposites and the values are listed in Table 2 . The incorporation of MWCNT to the hybrid epoxy matrixes did not present any tendency regarding the $T_{\mathrm{g}}$ values for hybrid epoxy matrixes. Thus, the oscillation of $T_{\mathrm{g}}$ values depends not only on how the free volume is affected by MWCNT incorporation, but also depends on the interaction between MWCNT and epoxy matrix which is subjected to different molecular architectures or condensation degrees.

Once FTIR analysis (Figure 1) revealed that a high cure degree was achieved for both matrixes (neat and hybrid epoxy), the decrease of $T_{\mathrm{g}}$ values for nanocomposites in relation to LY-CNT could be hindered by MWCNT incorporation in the reaction between the $\mathrm{NH}_{2}$ group of APTES/PTES copolysilsesquioxane and the epoxy ring. Furthermore, this decrease of $T_{\mathrm{g}}$ may be associated with commercial CNT impurities. In general, reports shown ${ }^{27}$ that SWCNT and MWCNT may lead to a decrease and an increased or unchanged $\mathrm{Tg}$ values of the nanocomposites, respectively.

Other studies also reported decreases in the $T_{\mathrm{g}}$ value of DGEBA epoxy matrixes with the incorporation of $\mathrm{CNT}^{23,25,28}$. Furthermore, a decrease in the $T_{\mathrm{g}}$ value with the incorporation of a random ${ }^{5,7,8,29}$ or organized polysilsesquioxane structures ${ }^{2,30,31}$ in epoxy matrix have been reported in literature. On the other hand, in our previous work ${ }^{13}$, the incorporation of the APTES/PTES copolysilsesquioxane provided improvement on $T_{\mathrm{g}}$ up to $13{ }^{\circ} \mathrm{C}$ in relation to neat LY matrix.

The results of the TGA measurements of the hybrid nanocomposites and LY epoxy resin are showed in Figure 5. The hybrid nanocomposites and LY resin presented similar thermograms with only one main degradation event. The mass loss observed in the $100-250{ }^{\circ} \mathrm{C}$ range (approximately 2 to $4 \%$ ) can be attributed to (1) the loss of the retained

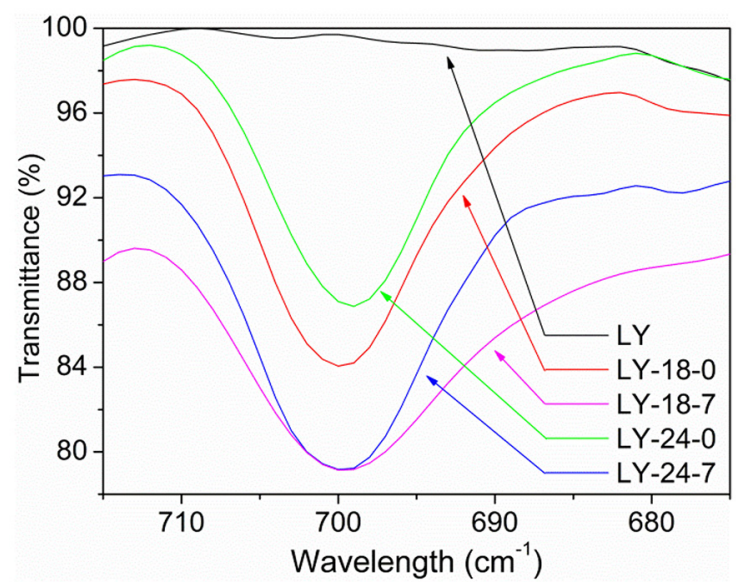

Figure 2. FTIR spectra in the range of $715-670 \mathrm{~cm}^{-1}$ of neat epoxy resin (LY) and the respective hybrid matrixes.

Table 2. Glass transition temperatures values obtained by dilatometry.

\begin{tabular}{cc}
\hline Samples & $T_{\mathrm{g}}\left({ }^{\circ} \mathbf{C}\right)$ \\
\hline LY & 121 \\
LY-CNT & 120 \\
LY-18-0-CNT & 116 \\
LY-18-7-CNT & 128 \\
LY-24-0-CNT & 109 \\
LY-24-7-CNT & 113 \\
\hline
\end{tabular}




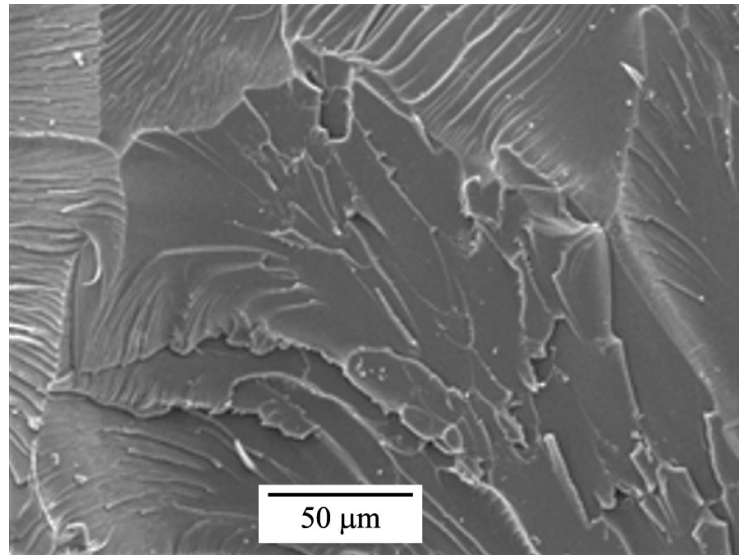

(a)

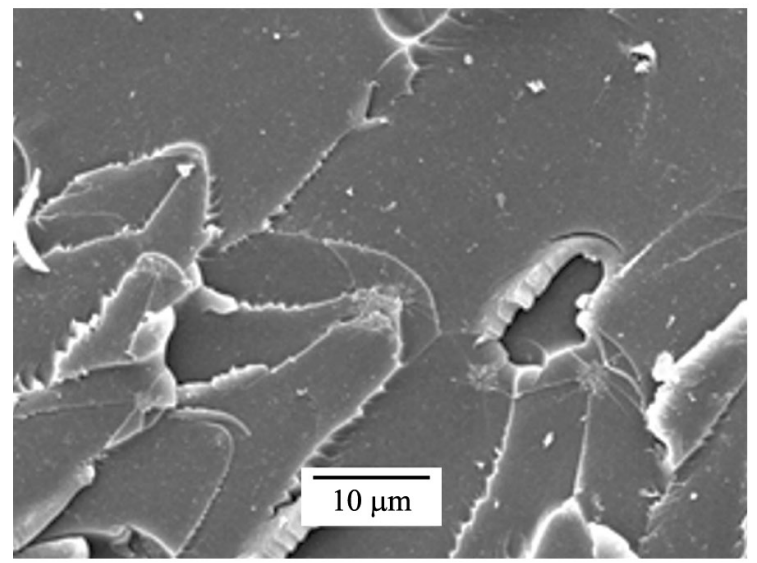

(c)

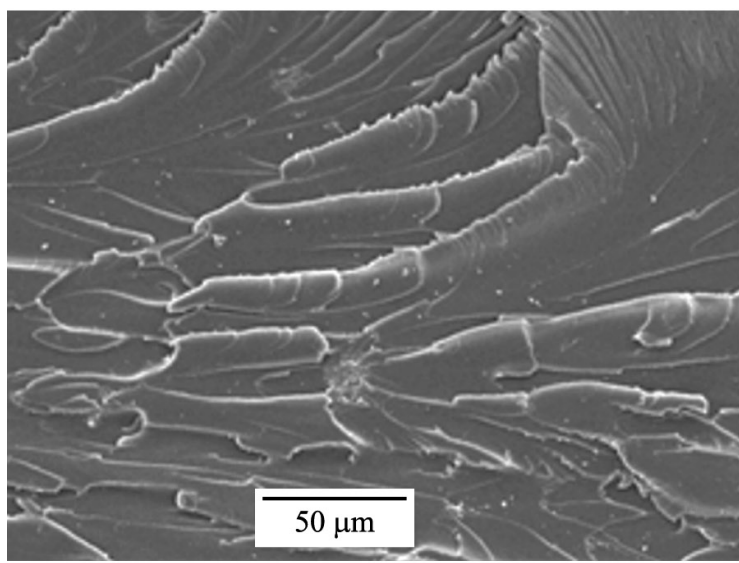

(e)

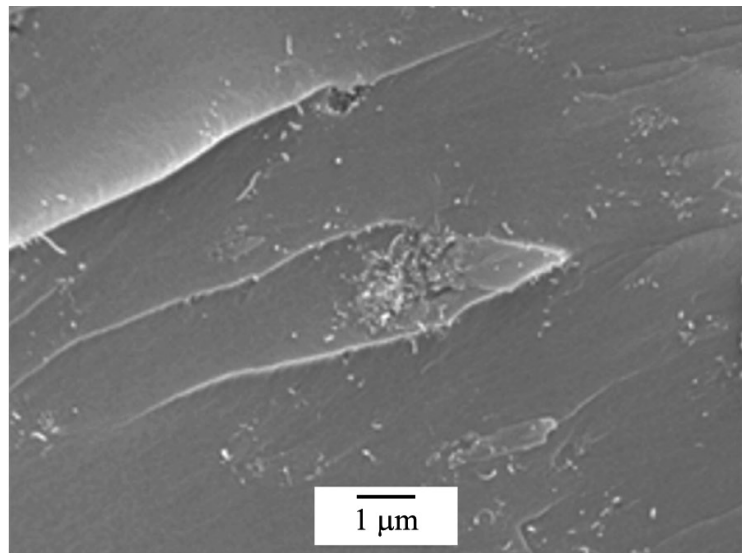

(b)

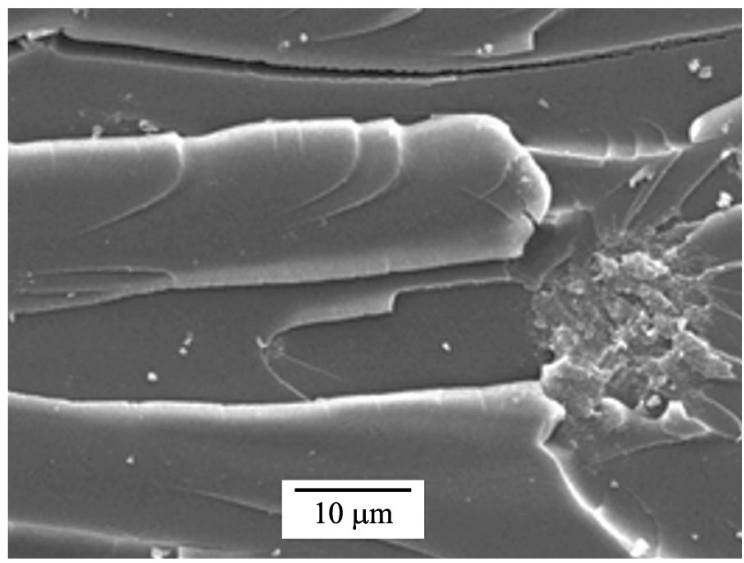

(d)

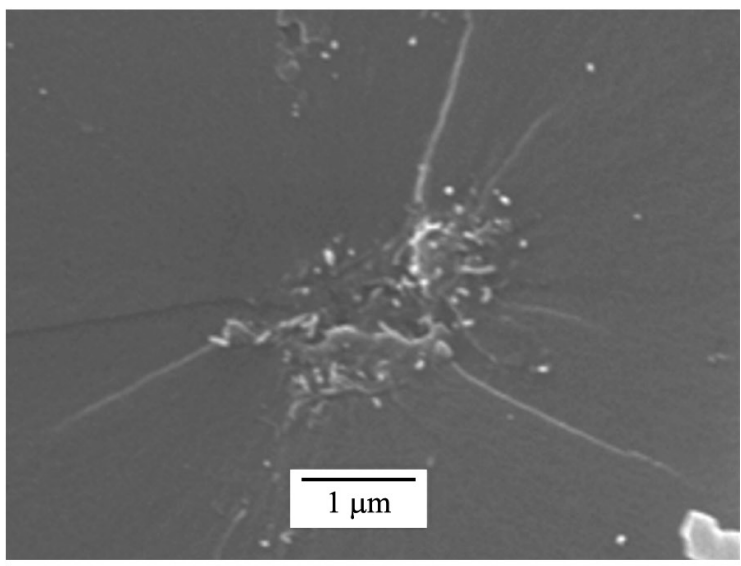

(f)

Figure 3. SEM images of fracture surface tensile: (a) LY; (b) LY-CNT; (c) LY-18-0-CNT; (d) LY-18-7-CNT; (e) LY-24-0-CNT; (f) LY-24-7-CNT.

volatiles in the hybrid matrix due to the incomplete polycondensation reactions of residual silanol ${ }^{32}$ or (2) the elimination of residual solvent (propanone) added during sonication stage ${ }^{17,33}$. Thermal stability parameters, including initial decomposing temperature (temperature of 5\% weight loss, $\left.\mathrm{T}_{\mathrm{d} 5}\right)$, temperature of $30 \%$ weight loss $\left(\mathrm{T}_{\mathrm{d} 30}\right)$, statistic heat-resistant index temperature $\left(\mathrm{T}_{\mathrm{s}}\right)$ and mass residual at $800^{\circ} \mathrm{C}$ are described in Table 3 . The percentages of volatiles were taken into account to obtain $\mathrm{T}_{\mathrm{d} 5}$ and $\mathrm{T}_{\mathrm{d} 30}$ values. $\mathrm{T}_{\mathrm{s}}$ value was determined from $\mathrm{T}_{\mathrm{d} 5}$ and $\mathrm{T}_{\mathrm{d} 30}$ values, according to the following equation ${ }^{34-36}$ :

$\mathrm{T}_{\mathrm{s}}=0.49\left[\mathrm{~T}_{\mathrm{d} 5}+0.6 \mathrm{x}\left(\mathrm{T}_{\mathrm{d} 30}-\mathrm{T}_{\mathrm{d} 5}\right)\right]$

$\mathrm{T}_{\mathrm{d} 5}$ value of the hybrids nanocomposites increased around 4 to $7^{\circ} \mathrm{C}$ in relation to the DGEBA epoxy resin. 
Table 3. Thermal stability parameters obtained from TGA of the hybrid nanocomposites.

\begin{tabular}{ccccc}
\hline Samples & $\mathbf{T}_{\mathrm{d} 5}\left({ }^{\circ} \mathbf{C}\right)$ & $\mathbf{T}_{\mathrm{d} 3 \mathbf{0}}\left({ }^{\circ} \mathbf{C}\right)$ & $\mathbf{T}_{\mathbf{s}}\left({ }^{\circ} \mathbf{C}\right)$ & $\begin{array}{c}\text { Residual mass at } \\
\mathbf{8 0 0}{ }^{\circ} \mathbf{C}(\mathbf{\%})\end{array}$ \\
\hline LY & 337 & 378 & 177.2 & 9.2 \\
LY-CNT & 332 & 377 & 175.9 & 2.7 \\
LY-18-0-CNT & 344 & 381 & 179.4 & 19.2 \\
LY-18-7-CNT & 341 & 387 & 180.6 & 18.0 \\
LY-24-0-CNT & 343 & 385 & 180.4 & 20.2 \\
LY-24-7-CNT & 344 & 382 & 179.7 & 20.0 \\
\hline
\end{tabular}

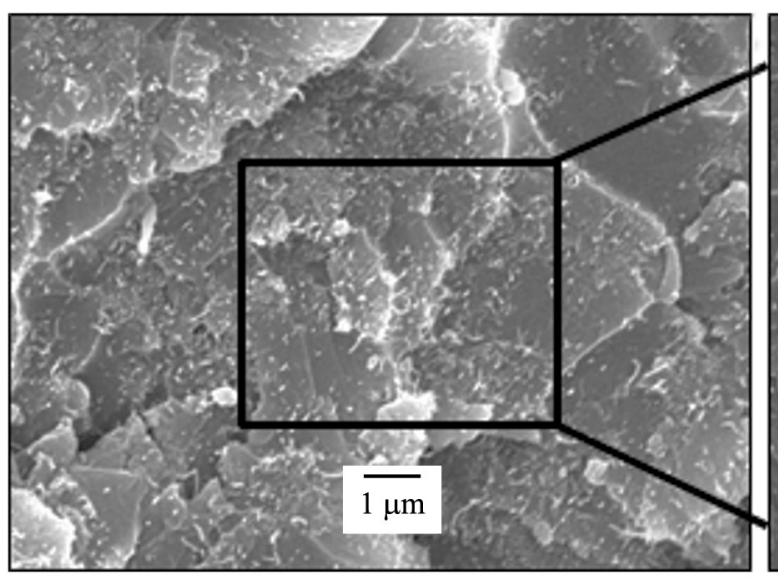

(a)

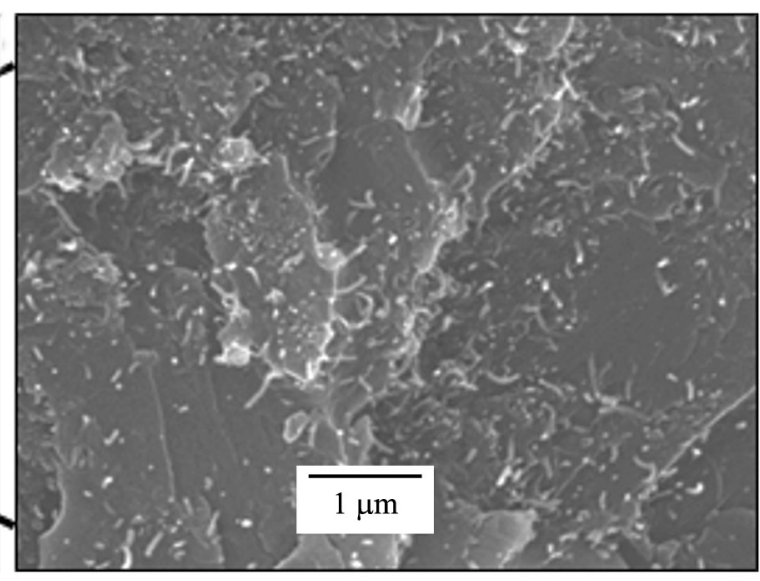

(b)

Figure 4. Regions of high concentration of MWCNT in the LY-18-0-CNT hybrid matrix.

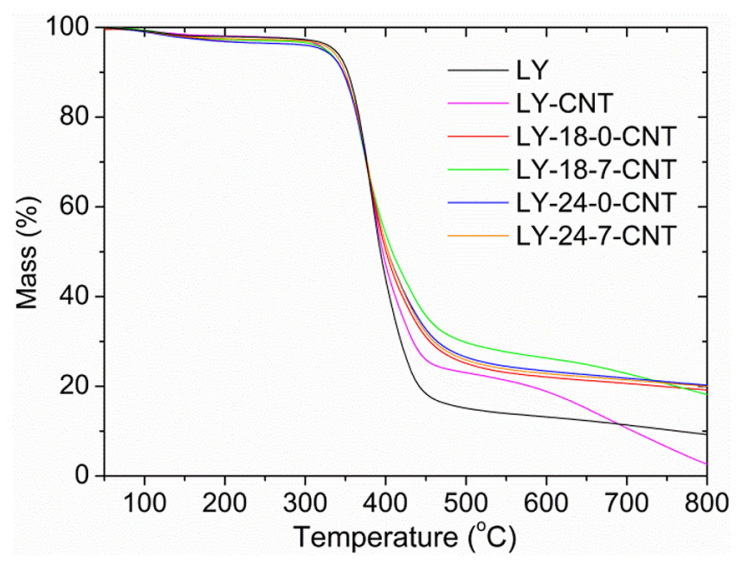

Figure 5. TGA thermograms of hybrid nanocomposites.

This behavior was also observed for $\mathrm{T}_{\mathrm{d} 30}$ value, however in this case, the increase was around 3 and $9{ }^{\circ} \mathrm{C}$. On the other hand, the incorporation of $0.25 \mathrm{wt} \% \mathrm{MWCNT}$ to the neat LY nanocomposite (LY-CNT) caused a decrease around $5{ }^{\circ} \mathrm{C}$ in $\mathrm{T}_{\mathrm{d} 5}$ value and no significant change was observed to $\mathrm{T}_{\mathrm{d} 30}$ value. The $T_{s}$ value for DGEBA epoxy resin is in agreement to the reported values in literature ${ }^{8}$ for similar DGEBA epoxy resin in terms of eq $\mathrm{g}^{-1}$, however, in the present work, a slight increase of this parameter was observed, contrary to other reported works.

Analyzing the residual mass at $800{ }^{\circ} \mathrm{C}$, it is clearly observed that the residual mass of the hybrid nanocomposites were higher than those obtained to LY and LY-CNT samples. The esidual mass values at $800^{\circ} \mathrm{C}$ for the hybrid nanocomposites were twice that of LY and LY-CNT samples. This significant increase in the residual mass is due to the high thermal stability of $\mathrm{Si}-\mathrm{O}-\mathrm{Si}$ bonds present in the APTES/PTES copolysilsesquioxanes ${ }^{13,32,37}$. The incorporation of MWCNT to LY resin caused an almost fully degradation of the matrix at $800^{\circ} \mathrm{C}$. This thermal stability decrease was also observed in literature ${ }^{23}$ and is attributed to the high thermal conductivity of carbon nanotubes, which favored the degradation process of the epoxy matrix. As reported by Puglia and co-workers ${ }^{38}$ the residual mass of epoxy resins can vary with their nature and processing conditions; for aromatic systems these differences were attributed to char formation properties. For example, a sensible higher residual mass is obtained for lower heating rates while at higher rates (ca. $30{ }^{\circ} \mathrm{C} \mathrm{min}^{-1}$ ) almost no residual mass remains at the end of the degradation step. As the carbon nanotubes can enhance the local heating transfer, it also affects the degradation process, lowering the residue amount.

On the other hand, the CNT presence in the epoxy/silsesquioxane matrixes did not favored the degradation of theses matrices, confirming the higher thermal stability provided by silsesquioxanes ${ }^{5,9}$.

\subsection{Mechanical characterization}

A typical curve obtained from mechanical test of LY sample is shown in Figure 6. All samples prepared in this work do not show any plastic deformation, failing during elastic 


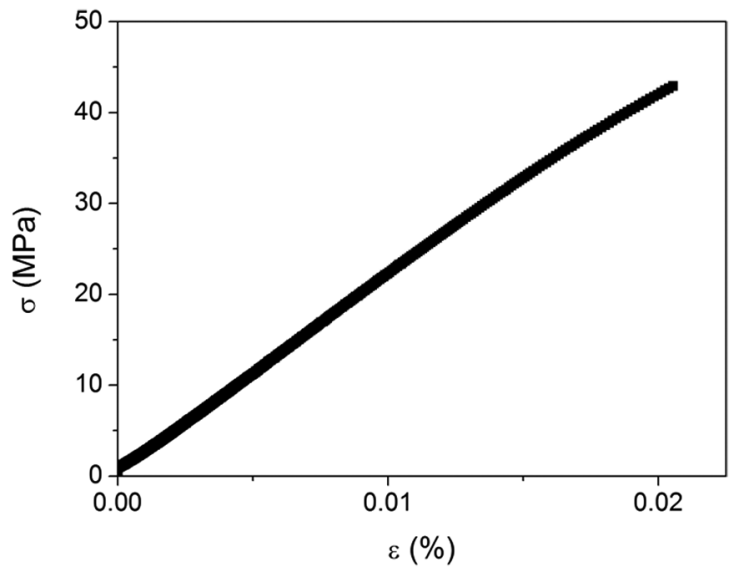

Figure 6. Stress-strain curve obtained from mechanical test of LY sample.

Table 4. Young's modulus (E) and tensile strength $\left(\sigma_{\max }\right)$ mean values obtained by mechanical tests. Values between parentheses are the standard deviation with $\alpha=0.05$.

\begin{tabular}{ccc}
\hline Samples & $\mathbf{E}(\mathbf{G P a})$ & $\boldsymbol{\sigma}_{\max }(\mathbf{M P a})$ \\
\hline LY & $2.1( \pm 0.1)$ & $41.0( \pm 5.4)$ \\
LY-CNT & $2.2( \pm 0.3)$ & $39.3( \pm 5.0)$ \\
LY-18-0-CNT & $2.6( \pm 0.8)$ & $41.3( \pm 6.2)$ \\
LY-18-7-CNT & $1.9( \pm 0.2)$ & $47.0( \pm 1.5)$ \\
LY-24-0-CNT & $2.1( \pm 0.1)$ & $43.0( \pm 5.7)$ \\
LY-24-7-CNT & $2.1( \pm 0.3)$ & $37.8( \pm 7.2)$ \\
\hline
\end{tabular}

deformation. This brittle behavior showed by all samples is in agreement with observed by SEM images. Student's $t$-tests were performed to compare the main values obtained in mechanical testing (Table 4) of the hybrid nanocomposites and their respective hybrid matrices. Confidence limit of $95 \%$ (with significance level, $\alpha=0.05$ ) was adopted.

The incorporation of MWCNT into epoxy matrix, in general, did not statistically affect the Young's modulus and tensile strength of the nanocomposites (according to the applied $t$-test). The only statistically significant difference in Young's modulus was observed for LY-18-0-CNT, when an increase of $24 \%$ was observed with the incorporation of

\section{References}

1. Chen H, Jacobs $\mathrm{O}, \mathrm{Wu} \mathrm{W}$, Rüdiger $\mathrm{G}$ and Schädel B. Effect of dispersion method on tribological properties of carbon nanotube reinforced epoxy resin composites. Polymer Testing. 2007; 26(3):351-360. http://dx.doi.org/10.1016/j. polymertesting.2006.11.004.

2. Ramírez C, Rico M, Torres A, Barral L, López J and Montero B. Epoxy/POSS organic-inorganic hybrids: ATR-FTIR and DSC studies. European Polymer Journal. 2008; 44(10):3035-3045. http://dx.doi.org/10.1016/j.eurpolymj.2008.07.024.

3. Patankar SN, Mohan R, Kelkar AD and Vaidyanathan R. Processing and characterization of epoxy resin dispersed with multi walled carbon nanotube (MWNT) derived from camphor. Materials Science and Engineering A. 2011; 529:253-256. http://dx.doi.org/10.1016/j.msea.2011.09.025.
$0.25 \%$ MWCNT. Although the MWCNT incorporation did not affect the Young's modulus of LY-18-7-CNT nanocomposite, an increase of $15 \%$ was observed in its tensile strength in relation to LY matrix. In this context, Patankar and co-workers ${ }^{3}$ also prepared nanocomposites based on epoxy/MWCNT by sonication technique and reported an improvement of $9 \%$ in the tensile strength with a loading of $0.15 \%$ MWCNT.

Assuming no chemical incompatibility between hybrid matrix and MWCNT, the mechanical properties are in agreement with SEM images (Figures 3 and 4) in which MWCNT clusters and a relatively poor dispersion was observed. These regions with high MWCNT concentration may lead to a lower charge transfer through the matrix/reinforcement interface, avoiding improvements in mechanical tests ${ }^{14,16,26}$. The heterogeneity observed in SEM images lead us to conclude that there is no tendency regarding the improvement of mechanical properties with MWCNT incorporation.

\section{Conclusions}

A new kind of hybrid nanocomposites based on epoxy/MWCNT was prepared by chemical modification of the epoxy matrix and dispersion of MWCNT by sonication. FTIR spectra showed that a high degree of cure was achieved, suggesting that the MWCNT loading did not affect the curing reaction of these hybrid matrices. Morphological observations of tensile fractured surfaces of the nanocomposites made by SEM revealed some regions with high MWCNT concentration, suggesting that the dispersion of pristine MWCNT by sonication technique is still a challenge. TGA results indicated that MWCNT incorporation reduced the thermal stability of epoxy matrix; on the other hand, the hybrid nanocomposite exhibited improvements in all the studied thermal stability parameters. Hybrid nanocomposites increased the Young's modulus and the maximum stress of the epoxy matrix up to $2.6 \mathrm{GPa}$ and $47 \mathrm{MPa}$, respectively. The results show that the novel hybrid nanocomposite is suitable for applications requiring superior thermal stability, such as special coatings for aeronautical components.

\section{Acknowledgements}

The authors are grateful to Brazilian Space Agency (AEB) by financial support and CAPES-DS to scholarship to M. A. de Farias.

4. Costa ML, Rezende MC and Pardini LC. Métodos de estudo da cinética de cura de resinas epóxi. Polímeros: Ciência e Tecnologia. 1999; 9(2):37-44. http://dx.doi.org/10.1590/S010414281999000200011 .

5. Macan J, Ivankovic H, Ivankovic M and Mencer HJ. Synthesis and characterization of organic-inorganic hybrids based on epoxy resin and 3-glycidyloxypropyltrimethoxysilane. Journal of Applied Polymer Science. 2004; 92(1):498-505. http://dx.doi. org/10.1002/app.20024.

6. Jiao J, Wang L, Lv P, Cui Y and Miao J. Improved dielectric and mechanical properties of silica/epoxy resin nanocomposites prepared with a novel organic-inorganic hybrid mesoporous silica: POSS-MPS. Materials Letters. 2014; 129:16-19. http:// dx.doi.org/10.1016/j.matlet.2014.05.010. 
7. Chiu Y-C, Ma C-CM, Liu F-Y, Chiang C-L, Riang L and Yang $\mathrm{J}-\mathrm{C}$. Effect of $\mathrm{P} / \mathrm{Si}$ polymeric silsesquioxane and the monomer compound on thermal properties of epoxy nanocomposite. European Polymer Journal. 2008; 44(4):1003-1011. http:// dx.doi.org/10.1016/j.eurpolymj.2008.01.033.

8. Chiu Y-C, Liu F-Y, Ma C-CM, Chou I-C, Riang L, Chiang $\mathrm{C}-\mathrm{L}$, et al. Syntheses and characterization of novel $\mathrm{P} / \mathrm{Si}$ polysilsesquioxanes/epoxy nanocomposites. Thermochimica Acta. 2008; 473(1-2):7-13. http://dx.doi.org/10.1016/j. tca.2008.03.020.

9. Zhang W, Li X, Jiang Y and Yang R. Investigations of epoxy resins flame-retarded by phenyl silsesquioxanes of cage and ladder structures. Polymer Degradation \& Stability. 2013; 98(1):246254. http://dx.doi.org/10.1016/j.polymdegradstab.2012.10.005.

10. Ni Y and Zheng S. Epoxy resin containing polyphenylsilsesquioxane: preparation, morphology, and thermomechanical properties. Journal of Polymer Science. Part A, Polymer Chemistry. 2006; 44(3):1093-1105. http://dx.doi.org/10.1002/pola.21222.

11. Sun D, Hu L, Zhang X and Lu Z. Nanostructures and properties of hybrid films based on DGEBA and modified with APES/PGE polyhedral oligomeric silsesquioxanes. Colloids and Surfaces. A, Physicochemical and Engineering Aspects. 2008; 313-314:278281. http://dx.doi.org/10.1016/j.colsurfa.2007.04.110.

12. Wu K, Song L, Hu Y, Lu H, Kandola BK and Kandare E. Synthesis and characterization of a functional polyhedral oligomeric silsesquioxane and its flame retardancy in epoxy resin. Progress in Organic Coatings. 2009; 65(4):490-497. http://dx.doi.org/10.1016/j.porgcoat.2009.04.008.

13. Farias MA, Coelho LAF and Pezzin SH. Epoxy/silsesquioxane organic - inorganic hybrids: sol-gel synthesis of inorganic precursors containing amino and phenyl groups. Polymer Engineering and Science. 2012; 52(1):52-61. http://dx.doi. org/10.1002/pen.22044.

14. Coleman JN, Khan U, Blau WJ and Gun'ko YK. Small but strong: a review of the mechanical properties of carbon nanotube-polymer composites. Carbon. 2006; 44(9):16241652. http://dx.doi.org/10.1016/j.carbon.2006.02.038.

15. Cividanes LS, Simonetti EAN, Moraes MB, Fernandes FW and Thim GP. Influence of carbon nanotubes on epoxy resin cure reaction using different techniques: a comprehensive review. Polymer Engineering and Science. 2013; 54(11):2461-2469. http://dx.doi.org/10.1002/pen.23775.

16. Gojny F, Wichmann M, Fiedler B and Schulte K. Influence of different carbon nanotubes on the mechanical properties of epoxy matrix composites - a comparative study. Composites Science and Technology. 2005; 65(15-16):2300-2313. http:// dx.doi.org/10.1016/j.compscitech.2005.04.021.

17. Suave J, Coelho LAF, Amico SC and Pezzin SH. Effect of sonication on thermo-mechanical properties of epoxy nanocomposites with carboxylated-SWNT. Materials Science and Engineering A. 2009; 509(1-2):57-62. http://dx.doi. org/10.1016/j.msea.2009.01.036.

18. Xie X, Mai Y and Zhou X. Dispersion and alignment of carbon nanotubes in polymer matrix: a review. Materials Science and Engineering R Reports. 2005; 49(4):89-112. http://dx.doi. org/10.1016/j.mser.2005.04.002.

19. American Society for Testing and Materials - ASTM. ASTM E1545-11: standard test method for assignment of the glass transition temperature by thermomechanical analysis. West Conshohocken: ASTM; 2011.

20. American Society for Testing and Materials - ASTM. ASTM D638-14: standard test method for tensile properties of plastics. West Conshohocken: ASTM; 2014.
21. Shechter L, Wynstra J and Kurkjy RP. Glycidyl ether reactions with amines. Industrial \& Engineering Chemistry. 1956; 48(1):94-97. http://dx.doi.org/10.1021/ie50553a029.

22. Bellamy LJ. The infra-red spectra of complex molecules. 2nd ed. New York: John Wiley \& Sons; 1957.

23. Puglia D, Valentini L, Armentano I and Kenny JM. Effects of single-walled carbon nanotube incorporation on the cure reaction of epoxy resin and its detection by Raman spectroscopy. Diamond and Related Materials. 2003; 12(3-7):827-832. http:// dx.doi.org/10.1016/S0925-9635(02)00358-8.

24. Yang K, Gu M and Jin Y. Cure behavior and thermal stability analysis of multiwalled carbon nanotube/epoxy resin nanocomposites. Journal of Applied Polymer Science. 2008; 110(5):2980-2988. http://dx.doi.org/10.1002/app.28898.

25. Tao K, Yang S, Grunlan JC, Kim YS, Dang B, Deng Y, et al. Effects of carbon nanotube fillers on the curing processes of epoxy resin-based composites. Journal of Applied Polymer Science. 2006; 102(6):5248-5254. http://dx.doi.org/10.1002/ app. 24773.

26. Fiedler B, Gojny FH, Wichmann MHG, Nolte MCM and Schulte K. Fundamental aspects of nano-reinforced composites. Composites Science and Technology. 2006; 66(16):3115-3125. http://dx.doi.org/10.1016/j.compscitech.2005.01.014.

27. Allaoui A and El Bounia N. How carbon nanotubes affect the cure kinetics and glass transition temperature of their epoxy composites? - a review. Express Polymer Letters. 2009; 3(9):588594. http://dx.doi.org/10.3144/expresspolymlett.2009.73.

28. Ganguli S, Aglan H, Dennig P and Irvin G. Effect of loading and surface modification of MWCNTs on the fracture behavior of epoxy nanocomposites. Journal of Reinforced Plastics and Composites. 2005; 25(2):175-188. http://dx.doi. org/10.1177/0731684405056425.

29. Liu H, Zheng S and Nie K. Morphology and thermomechanical properties of organic-inorganic hybrid composites involving epoxy resin and an incompletely condensed polyhedral oligomeric silsesquioxane. Macromolecules. 2005; 38(12):5088-5097. http://dx.doi.org/10.1021/ma0504318.

30. Li GZ, Wang L, Toghiani H, Daulton TL, Koyama K and Pittman CU. Viscoelastic and mechanical properties of epoxy/multifunctional polyhedral oligomeric silsesquioxane nanocomposites and epoxy/ladderlike polyphenylsilsesquioxane blends. Macromolecules. 2001; 34(25):8686-8693. http://dx.doi. org/10.1021/ma011117q

31. Rashid ESA, Ariffin K, Kooi CC and Akil HM. Preparation and properties of POSS/epoxy composites for electronic packaging applications. Materials \& Design. 2009; 30(1):1-8. http://dx.doi. org/10.1016/j.matdes.2008.04.065.

32. Li YS, Wang Y and Ceesay S. Vibrational spectra of phenyltriethoxysilane, phenyltrimethoxysilane and their sol-gels. Spectrochimica Acta. Part A: Molecular and Biomolecular Spectroscopy. 2009; 71(5):1819-1824. http://dx.doi.org/10.1016/j. saa.2008.04.027. PMid:18722154.

33. Lau K, Lu M, Cheung H, Sheng F and Li H. Thermal and mechanical properties of single-walled carbon nanotube bundlereinforced epoxy nanocomposites: the role of solvent for nanotube dispersion. Composites Science and Technology. 2005; 65(5):719725. http://dx.doi.org/10.1016/j.compscitech.2004.10.005.

34. Lehrle R and Williams R. Thermal degradation of bacterial poly (hydroxybutyric acid): mechanisms from the dependence of pyrolysis yields on sample thickness. Macromolecules. 1994; 27(14):3782-3789. http://dx.doi.org/10.1021/ma00092a017.

35. Grimbley MR and Lehrle RS. The thermal degradation mechanism of polyisobutylene. Part 1: comparison of results with statistical predictions provides a general interpretation of 
the mechanisms of decomposition. Polymer Degradation \& Stability. 1995; 49(2):223-229. http://dx.doi.org/10.1016/01413910(95)87003-2.

36. Bibiao J, Jianjun H, Wenyun W, Luxia J and Xinxian C. Synthesis and properties of novel polybismaleimide oligomers. European Polymer Journal. 2001; 37(3):463-470. http://dx.doi. org/10.1016/S0014-3057(00)00147-6.
37. Yoshinaga I, Yamada N and Katayama S. Effect of metal alkoxide complexes on condensation reactions of hydrolyzed phenyltriethoxysilane. Journal of Sol-Gel Science and Technology. 2003; 28(1):65-70. http://dx.doi.org/10.1023/A:1025637103740.

38. Puglia D, Manfredi LB, Vazquez A and Kenny JM. Thermal degradation and fire resistance of epoxy-amine-phenolic blends. Polymer Degradation \& Stability. 2001; 73(3):521-527. http:// dx.doi.org/10.1016/S0141-3910(01)00157-4. 